\title{
What is the role of sporadic phloem sap nitrate?
}

\author{
Jing Cui ${ }^{1}$, Andreas D. Peuke ${ }^{2}$, Anis Limami ${ }^{3}$, and Guillaume Tcherkez ${ }^{4}$ \\ ${ }^{1} \mathrm{ANU}$ \\ ${ }^{2} \mathrm{ADP}$ International Plant Science Consulting \\ ${ }^{3}$ University of Angers, (IRHS 1345) Institute of Research of Horticulture and Seeds \\ ${ }^{4}$ Affiliation not available
}

January 20, 2021

\begin{abstract}
Since the first description of phloem sap composition nearly 60 years ago, it is generally assumed that phloem sap does not contain nitrate and that there is little or no backflow of nitrate from shoots to roots. While it is true that nitrate can occasionally be absent from phloem sap, there is now substantial evidence that phloem can carry nitrate and furthermore, transporters involved in nitrate redistribution to shoot sink organs and roots have been found. This raises the question of why nitrate may or may not be present in phloem sap, why its concentration is generally kept low, and whether plant shoot-root nutrient cycling also involves nitrate. We propose here that phloem sap nitrate is not only an essential component of plant nutritional signaling but also contributes to physical properties of phloem sap and as such, its concentration is controlled to ensure proper coordination of plant development and nutrient transport.
\end{abstract}

\section{Introduction}

It has now been 61 years since phloem sap composition has first been described, using sap extracted from willow (Peel \& Weatherley, 1959). In that study, using colorimetric methods, nitrate was found to be undetectable. Several subsequent studies also reported the absence of nitrate in other species such as castor bean (Ricinus communis ) (Hall \& Baker, 1972) and overviews of phloem sap composition established the generally very low, or undetectable, concentration in phloem sap nitrate (Ziegler, 1975). Furthermore, experiments with ${ }^{15} \mathrm{~N}$-nitrate labelling in legumes have shown that nitrate could not be transported from xylem to phloem at detectable levels (Pate et al. , 1975). There are more recent reports where nitrate was found to be undetectable, for example in maize (Lohauset al. , 2000). It is thus widely accepted that phloem sap nitrate is of negligible importance and in particular, that nitrate circulation from shoots to roots does not occur. For example, in a recent review, the backflow of nitrate via the phloem to regulate root development is not mentioned (Fig. 3 in (Tegeder \& Masclaux-Daubresse, 2018)). Also, in textbooks and university lectures, it is often reported that nitrate is absent from phloem sap and thus does not flow back from shoots to roots, see for example (Taiz et al. , 2015). However, many pieces of recent evidence suggest the contrary and provide possible reasons explaining why phloem nitrate concentration is usually low.

\section{Phloem sap may contain nitrate}

In fact, there are noticeable exceptions where nitrate is not absent from phloem sap composition (Fig. 1). It is the case of cereals (wheat, rice), with phloem sap nitrate of up to $8 \mathrm{mM}$ (Hayashi \& Chino, 1985; Hayashi \& Chino, 1986). Also, in palm trees, nitrate has been found in phloem exudates for either trunk and inflorescence peduncles (van Die \& Tammes, 1975). Extensive analysis of castor bean phloem sap has shown that average nitrate phloem concentration is $0.59 \mathrm{mM}$, ranging from no detectability to $2.4 \mathrm{mM}$ (Peuke, 2010). This is of course much less than in xylem, which contains up to $25 \mathrm{mM}$ nitrate. Interestingly, nitrate has been found to be much more abundant in phloem $(0.29 \mathrm{mM})$ than xylem sap $(3 \mu \mathrm{M})$ in Western candle 
tree (Banksia prionotes) (Jeschke \& Pate, 1995). These findings cannot be explained by the technique of sap collection (i.e. potential adulteration by other tissues upon sampling) since the above-cited studies used very different techniques (aphid-stylet and pure phloem sap bleeding) and therefore a systematic contamination is not a plausible explanation.

\section{Nitrate redistribution via phloem sap circulation}

Nitrate redistribution via phloem circulation has been recently suggested to occur in three physiological contexts (Fig. 1): remobilization from old leaves, development of reproductive structures and nitrate backflow from shoots to roots. In Arabidopsis, the nitrate transporter NPF5.5 is involved in controlling embryo N content: in knock-out mutants, embryos at the bent cotyledon stage have a 7-8\% reduction in the $\mathrm{N}$ content suggesting that the import of nitrate to the developing seed has been impacted (Léran et al. , 2015). There is presently no direct evidence that NPF5.5 only participates in the import of nitrate into seeds but its implication in nitrate transfer from the phloem to developing tissues is likely. NPF2.12/NRT1.6 appear to be expressed intensively in funiculus vascular bundles, which are mostly made of phloem tissue in Arabidopsis (Almagro et al. , 2008), and mutants affected in this transporter have altered isotopic $\left({ }^{13} \mathrm{~N}\right)$ nitrogen transfer to reproductive structures (Babst et al. , 2019). Three nitrate transporters have been shown to be involved in nitrate transfer and/or redistribution to the phloem from xylem or source nitrate-containing tissues: NPF2.13/NRT1.7, NPF1.1/NRT1.12, and NRT1.2/NRT1.11 (reviewed in (Iqbal et al. , 2020)). In particular, it has been recently shown that NRT1.7 is essential for remobilization of nitrate from old leaves to deliver nitrate into the phloem, making it available for new, developing leaves and enhancing nitrogen use efficiency (Chen et al. , 2020). Also, in mutants affected in NRT1.9 (transporter expressed in root phloem), the nitrate content in root phloem exudates is lower (by 20 to 30\%) (Wang \& Tsay, 2011); furthermore, downwards nitrate transport to root tips, when assayed with a compartmentalized root system, is reduced, suggesting that NRT1.9 plays a role in the backflow of nitrate to roots (Wang \& Tsay, 2011). Double mutants affected in both NRT1.11 and NRT1.12 have a strong growth phenotype suggesting that xylem-to-phloem nitrate transfer and/or phloem-mediated nitrate is essential for plant growth (Hsu \& Tsay, 2013). Taken as a whole, recent data on nitrate transporters clearly show that phloem can carry nitrate upwards (developing sink organs in shoots) and downwards (back to roots).

\section{Phloem sap nitrate is a signaling molecule}

There is now considerable evidence that nitrate can play a signaling role to control plant development (Kant, 2018). Historically, an important step forward was the demonstration that nitrate shoot content acts as a signal to regulate the shoot:root ratio. In fact, manipulating nitrate reductase activity showed a correlation between leaf nitrate concentration and shoot:root ratio, across different levels of nitrate supply (Scheible et al. , 1997). Furthermore, in split-root experiments, root growth is inhibited by the accumulation of nitrate in the shoot, regardless of the fact that one part of the root system was supplied with high nitrate and the other part with low nitrate (Scheibleet al. , 1997). Molecular data have now demonstrated a link between nitrate and phytohormones, and this aspect has been reviewed recently elsewhere (Vega et al. , 2019). The signaling cascade associated with nitrate has also been dissected recently and shown to involve $\mathrm{Ca}^{2+}$-sensor protein kinases and NIN-like proteins (NLP) transcription factors to control gene expression, including gene encoding enzymes and transporters involved in nitrogen assimilation (Liu et al. , 2017; Chu et al. , 2020). The role played by nitrate as a signal from shoots to roots implies that its concentration in phloem must be controlled to avoid both fluctuations and high concentrations. That is, signal-carrying molecules have to be at low concentration under steady-state conditions and their transient increase can play the role of a signal. Unfortunately, relatively little is known on possible fluctuations of nitrate concentration in phloem sap and whether its appearance in sap is linked to specific circumstances (but see below, Perspectives for $N$ cycling in plants ). It is worth noting that in root tips, nitrate absorption is small, compared to other root parts (Lazof et al. , 1992). In addition, root tips are the sites of longitudinal root growth (increase in root length), where protophloem develops first (i.e. before protoxylem) (Mahonen et al. , 2000; Bauby et al. , 2007). It is plausible that downwards transport of nitrate via (proto)phloem plays a role in controlling root tip nitrate concentration and thus root growth. 


\section{Low nitrate concentration may avoid protein aggregation}

Phloem sap contains very high content of sucrose (about $400 \mathrm{mM}$ in castor bean), amino acids (about $60 \mathrm{mM}$ ) and $\mathrm{K}^{+}$(about $60 \mathrm{mM}$ ). $\mathrm{Mg}^{2+}$ and $\mathrm{Na}^{+}$are present in lower abundance and $\mathrm{Ca}^{2+}$ is at low concentration $(1$ $\mathrm{mM}$ or less) (Ziegler, 1975). Anions that counterbalance $\mathrm{K}^{+}$high content are mostly $\mathrm{Cl}^{-}$, phosphate, sulphate and organic acids (malate). Nitrate is thus a minor participant in phloem electroneutrality. Also, phloem sap contains significant amounts of proteins, at about $1 \mathrm{~g} \mathrm{~L}^{-1}$, and an important proportion is made of the so-called P-proteins (SEOR proteins inArabidopsis ) that are believed to play a role in phloem occlusion by $\mathrm{Ca}^{2+}$-dependent aggregation (Anstead et al. , 2012; Jekat et al. , 2013; Knoblauch et al. , 2014; van Belet al. , 2014). Of course, phloem sap contains many other proteins, and recent proteomics analyses have shown that this includes not only enzymes, but also translation initiation or elongation factors, proteins involved in redox homeostasis, chaperones, etc. (Rodriguez-Celma et al. , 2016). It is worth mentioning that with such high salt concentration (in particular $\mathrm{K}^{+}$), there is a risk of uncontrolled protein aggregation. In fact, both experiments and theory have provided evidence that ion species have different propensity to trigger protein aggregation (chaotropism), via denaturation and/or instability (Kunz, 2010). $\mathrm{Ca}^{2+}$ is the most chaotropic cation while tertiary amines are the least chaotropic, $\mathrm{K}^{+}$being intermediate. This provides a physical justification for the role of $\mathrm{Ca}^{2+}$ in phloem occlusion. Similarly for anions, phosphate, sulphate and organic acids are the least chaotropic, but nitrate is much more chaotropic, just behind perchlorate and iodide (Kunz, 2010). Accordingly, experiments with lysozyme have demonstrated that the displacement of the solubilization-aggregation equilibrium towards aggregation is larger with nitrate than chloride forms of sodium salts (Kastelic et al. , 2015). As such, having high concentrations of nitrate is not desirable for phloem protein stability when $\mathrm{K}^{+}$(and/or $\mathrm{Mg}^{2+}$ ) is present at high concentration. Conversely, in sucrose concentrated solutions (like phloem sap), ethylamine nitrate is beneficial to protein renaturation and decreases viscosity due to the rescuing property of ethylamine as a non-chaotropic cation (Byrneet al. , 2007).

\section{Perspectives for $\mathbf{N}$ cycling in plants}

While there are good reasons to explain why nitrate concentration must remain low in phloem sap (signaling and chaotropism), the occasional presence of nitrate raises the question of its potential role in nutrient cycling. Pioneering $\mathrm{N}$ mass balance in castor bean proposed that nearly $50 \%$ of nitrate translocated to the shoot cycled back to roots (Marschner et al. , 1997). While this number is certainly overestimated, recent isotopic data $\left({ }^{15} \mathrm{~N}\right.$ natural abundance, $\left.\delta^{15} \mathrm{~N}\right)$ also suggest that a small flux of a few percent of xylem translocation to shoots can cycle back to roots, in both sunflower and oil palm (Cui et al. , 2020). Although quantitatively minor, this flux is important to explain the natural ${ }^{15} \mathrm{~N}$-enrichment in root nitrate. It is also possible that variations in nitrate concentration, in addition to organic $\mathrm{N}$, contribute to the diel pattern of $\delta^{15} \mathrm{~N}$ of phloem in castor bean (Peuke et al. , 2013). The $\delta^{15} \mathrm{~N}$ value of aphids (feeding on phloem sap) has been shown to be lower (depleted) compared to host plants and related to nitrate reduction capacity, suggesting that the aphid-host isotopic difference is partly explained by the ${ }^{15} \mathrm{~N}$-enrichment in phloem nitrate - as opposed to the ${ }^{15} \mathrm{~N}$-depletion in phloem amino acids (Wilson et al. , 2011).

The backflow of nitrate from shoots to roots depends on growth conditions impacting on overall nutrition, since (Cui et al. , 2020) showed it depends on K nutrition and root hypoxia (waterlogging). Also, phloem sap nitrate increases when nitrate availability increases and declines with salinity (Peuke et al. , 1996). Surprisingly, meta-analyses have shown that phloem nitrate concentration does not correlate significantly to other cations and only correlates with xylem, leaf and root nitrate content (Peuke, 2010). However, the nitrate flow in the phloem (expressed in $\mu$ mol nitrate $\mathrm{g}^{-1} \mathrm{FW} \mathrm{d}^{-1}$ ) correlates reasonably well with phloem carbon and $\mathrm{Ca}^{2+}$ flows (Peuke, 2010). The nitrate backflow thus depends on other nutrients and salinity and is maybe linked to metabolites (organic acids and amino acids) present in phloem sap. The supply of amino acids to roots via the phloem participates in the control of root $\mathrm{N}$ acquisition (for a specific discussion, see (Tillardet al. , 1998)) and as discussed above, nitrate also plays a regulatory role. Thus, more than individual concentrations, the nitrate-to-amino acid ratio of phloem sap might be a crucial component of plant development, root growth and nitrogen assimilation. In the past years, there have been an increasing number 
of publications on phloem (including proteomics data) but due to the difficulty of phloem sap collection, there is limited information on phloem composition under varying conditions, including metabolite profiling (metabolomics), nitrate content and $\delta^{15} \mathrm{~N}$ value. Future studies are warranted to provide more data and therefore to appreciate the generality and significance of the transport of nitrate in the phloem.

\section{Acknowledgements}

The authors acknowledge the financial support of the Région Pays de la Loire and Angers Loire Métropole via the grant Connect Talent Isoseed awarded to G.T.

\section{Data availability}

There is no data associated with this manuscript.

\section{References}

Almagro A, Lin SH, Tsay YF. 2008. Characterization of theArabidopsis nitrate transporter NRT1.6 reveals a role of nitrate in early embryo development. The Plant Cell 20 : 3289-3299.

Anstead JA, Froelich DR, Knoblauch M, Thompson GA. 2012.Arabidopsis P-Protein Filament Formation Requires Both AtSEOR1 and AtSEOR2. Plant and Cell Physiology 53 : 1033-1042.

Babst BA, Gao F, Acosta-Gamboa LM, Karve A, Schueller MJ, Lorence A. 2019. Three NPF genes in Arabidopsis are necessary for normal nitrogen cycling under low nitrogen stress. Plant Physiology and Biochemistry 143 : 1-10.

Bauby H, Divol F, Truernit E, Grandjean O, Palauqui J-C. 2007.Protophloem differentiation in early Arabidopsis thalianadevelopment. Plant and Cell Physiology 48 : 97-109.

Byrne N, Wang L-M, Belieres J-P, Angell CA. 2007. Reversible folding-unfolding, aggregation protection, and multi-year stabilization, in high concentration protein solutions, using ionic liquids. Chemical Communications : 2714-2716.

Chen K-E, Chen H-Y, Tseng C-S, Tsay Y-F. 2020. Improving nitrogen use efficiency by manipulating nitrate remobilization in plants. Nature Plants 6 : 1126-1135.

Chu LC, Offenborn JN, Steinhorst L, Wu XN, Xi L, Li Z, Jacquot A, Lejay L, Kudla J, Schulze WX. 2020. Plasma membrane CBL $\mathrm{Ca}^{2+}$ sensor proteins function in regulating primary root growth and nitrate uptake by affecting global phosphorylation patterns and microdomain protein distribution. New Phytologist : In press.

Cui J, Lamade E, Fourel F, Tcherkez G. $2020 . \delta^{15} \mathrm{~N}$ values in plants are determined by both nitrate assimilation and circulation. New Phytologist 226 : 1696-1707.

Hall SM, Baker DA. 1972. The chemical composition ofRicinus phloem exudate. Planta 106 : 131-140.

Hayashi H, Chino M. 1985. Nitrate and other anions in the rice phloem sap. Plant and Cell Physiology 26 : 325-330.

Hayashi H, Chino M. 1986. Collection of pure phloem sap from wheat and its chemical composition. Plant and Cell Physiology27 : 1387-1393.

Hsu P-K, Tsay Y-F. 2013. Two phloem nitrate transporters, NRT1. 11 and NRT1. 12, are important for redistributing xylem-borne nitrate to enhance plant growth. Plant Physiology 163 : 844-856.

Iqbal A, Qiang D, Alamzeb M, Xiangru W, Huiping G, Hengheng Z, Nianchang P, Xiling Z, Meizhen S. 2020. Untangling the molecular mechanisms and functions of nitrate to improve nitrogen use efficiency. Journal of the Science of Food and Agriculture 100 : 904-914. 
Jekat SB, Ernst AM, von Bohl A, Zielonka S, Twyman RM, Noll GA, Prüfer D. 2013. P-proteins in Arabidopsis are heteromeric structures involved in rapid sieve tube sealing. Frontiers in Plant Science $\mathbf{4}$ : Article 225.

Jeschke WD, Pate JS. 1995. Mineral nutrition and transport in xylem and phloem of Banksia prionotes (Proteaceae), a tree with dimorphic root morphology. Journal of Experimental Botany46 : 895-905.

Kant S. 2018. Understanding nitrate uptake, signaling and remobilisation for improving plant nitrogen use efficiency.Seminars in Cell and Developmental Biology $\mathbf{7 4}:$ 89-96.

Kastelic M, Kalyuzhnyi YV, Hribar-Lee B, Dill KA, Vlachy V. 2015. Protein aggregation in salt solutions. Proceedings of the National Academy of Sciences 112 : 6766-6770.

Knoblauch M, Froelich DR, Pickard WF, Peters WS. 2014. SEORious business: structural proteins in sieve tubes and their involvement in sieve element occlusion. Journal of Experimental Botany65 : 18791893.

Kunz W. 2010. Specific ion effects in colloidal and biological systems. Current Opinion in Colloid $\mathcal{G}^{3}$ Interface Science15 : 34-39.

Lazof DB, Rufty TW, Redinbaugh MG. 1992. Localization of nitrate absorption and translocation within morphological regions of the corn root. Plant Physiology 100 : 1251-1258.

Léran S, Garg B, Boursiac Y, Corratgé-Faillie C, Brachet C, Tillard P, Gojon A, Lacombe B. 2015. AtNPF5.5, a nitrate transporter affecting nitrogen accumulation in Arabidopsis embryo.Scientific Reports 5 : Article 7962.

Liu K-h, Niu Y, Konishi M, Wu Y, Du H, Chung HS, Li L, Boudsocq M, McCormack M, Maekawa S. 2017. Discovery of nitrate-CPK-NLP signalling in central nutrient-growth networks. Nature 545 : 311-316.

Lohaus G, Hussmann M, Pennewiss K, Schneider H, Zhu JJ, Sattelmacher B. 2000. Solute balance of a maize (Zea mays L.) source leaf as affected by salt treatment with special emphasis on phloem retranslocation and ion leaching. Journal of Experimental Botany 51 : 1721-1732.

Mähönen AP, Bonke M, Kauppinen L, Riikonen M, Benfey PN, Helariutta Y. 2000. A novel two-component hybrid molecule regulates vascular morphogenesis of the Arabidopsis root. Genes and Development $14: 2938-2943$.

Marschner H, Kirkby EA, Engels C. 1997. Importance of cycling and recycling of mineral nutrients within plants for growth and development. Botanica Acta 110 : 265-273.

Pate JS, Sharkey PJ, Lewis OAM. 1975. Xylem to phloem transfer of solutes in fruiting shoots of legumes, studied by a phloem bleeding technique. Planta 122 : 11-26.

Peel AJ, Weatherley PE. 1959. Composition of sieve-tube sap. Nature 184 : 1955-1956.

Peuke A, Gessler A, Tcherkez G. 2013. Experimental evidence for diel $\delta^{15} \mathrm{~N}$-patterns in different tissues, xylem and phloem saps of castor bean (Ricinus communis L.). Plant, Cell and Environment 36 : 2219-2228.

Peuke AD. 2010. Correlations in concentrations, xylem and phloem flows, and partitioning of elements and ions in intact plants. A summary and statistical re-evaluation of modelling experiments inRicinus communis . Journal of Experimental Botany61 : 635-655.

Peuke AD, Glaab J, Kaiser WM, Jeschke WD. 1996. The uptake and flow of C, N and ions between roots and shoots in Ricinus communis L. IV. Flow and metabolism of inorganic nitrogen and malate depending on nitrogen nutrition and salt treatment. Journal of Experimental Botany 47 : 377-385. 
Rodríguez-Celma J, Ceballos-Laita L, Grusak MA, Abadía J, López-Millán A-F. 2016. Plant fluid proteomics: Delving into the xylem sap, phloem sap and apoplastic fluid proteomes. Biochimica et Biophysica Acta (BBA) - Proteins and Proteomics 1864 : 991-1002.

Scheible W-R, Lauerer M, Schulze E-D, Caboche M, Stitt M. 1997. Accumulation of nitrate in the shoot acts as a signal to regulate shoot-root allocation in tobacco. The Plant Journal 11 : 671-691.

Taiz L, Zeiger E, Moller I, Murphy A. 2015. Plant physiology and development . Sunderland, Massachusetts: Sinauer Associates Inc.

Tegeder M, Masclaux-Daubresse C. 2018. Source and sink mechanisms of nitrogen transport and use. New Phytologist 217 : 35-53.

Tillard P, Passama L, Gojon A. 1998. Are phloem amino acids involved in the shoot to root control of $\mathrm{NO}_{3}{ }^{-}$uptake in Ricinus communisplants? Journal of Experimental Botany 49 : 1371-1379.

van Bel AJE, Furch ACU, Will T, Buxa SV, Musetti R, Hafke JB. 2014. Spread the news: systemic dissemination and local impact of $\mathrm{Ca}^{2+}$ signals along the phloem pathway. Journal of Experimental Botany 65 : 1761-1787.

van Die J, Tammes P 1975. Phloem exudationfrom Monocotyledonous axes. In: Zimmermann M, Milburn J eds. Transport in plants I. Phloem transport . Berlin: Springer, 196-222.

Vega A, O'Brien JA, Gutiérrez RA. 2019. Nitrate and hormonal signaling crosstalk for plant growth and development. Current Opinion in Plant Biology 52 : 155-163.

Wang Y-Y, Tsay Y-F. 2011. Arabidopsis nitrate transporter NRT1.9 is important in phloem nitrate transport. The Plant Cell 23 : 1945-1957.

Wilson ACC, Sternberg LdSL, Hurley KB. 2011. Aphids alter host-plant nitrogen isotope fractionation. Proceedings of the National Academy of Sciences 108 : 10220-10224.

Ziegler H 1975. Nature of transported substances. In: Zimmermann M, Milburn J eds. Transport in plants I. Phloem transport . Berlin: Springer, 59-100.

\section{Hosted file}

image1.emf available at https://authorea.com/users/383909/articles/505039-what-is-the-roleof-sporadic-phloem-sap-nitrate

Figure 1. Nitrate circulation via phloem sap : (a-f) Typical species where phloem nitrate has been directly measured or inferred from isotopic mass-balance: palm trees (a), cereals (wheat and rice) (b), Western candle tree Banksia prionotes (c), castor bean (d), sunflower (e), and Arabidopsis (f). (g) Summary of hypothetical roles of nitrate circulation via phloem sap (see text for further details). 